\title{
Further evidence on coding in reading-disabled children
}

\author{
R. REED HUNT and ISIS BADAWI \\ University of North Carolina, Greensboro, North Carolina
}

\begin{abstract}
The experiment reported here used the release-from-proactive-inhibition paradigm to explore encoding differences between normal readers and reading-disabled children. The two groups performed comparably when the dimension of similarity was semantic or phonetic. Differences in performance were found with visually similar words. These data converge with those from other recent reports to raise serious questions about a strong form of the phonetic coding deficiency hypothesis of specific reading disability.
\end{abstract}

Specific reading disability has long attracted the attention of psychological research. The fascination of the phenomenon is that the reading-disabled child has enormous difficulty in reading but is apparently otherwise of normal intellect. Among the various current theoretical analyses of reading disability, perhaps the most popular is a phonetic coding deficiency (Liberman \& Shankweiler, 1980; Liberman, Shankweiler, Liberman, Fowler, \& Fischer, 1977; Perfetti \& Lesgold, 1978). On this view, reading disability is attributable to deficits in coding information into a phonetic form in short-term memory. Phonetic coding appears to be an important skill in normal reading (Baddeley \& Hitch, 1974; Conrad, 1972; Crowder, 1972), and the phonetic code is quite important in learning to read (Rozin \& Gleitman, 1977). Thus, phonetic coding deficiency is a plausible mechanism for reading disability.

Moreover, evidence consistent with the phonetic coding deficiency hypothesis has been obtained from phonetic confusability paradigms. Normal readers false-alarm more readily to a rhyming than to a nonrhyming distraction in recognition memory, but poor readers are not affected by the phonetic similarity of distractors and targets (Byrne \& Shea, 1979; Mark, Shankweiler, Liberman, \& Fowler, 1977). Normal readers are less likely to recall items if the items rhyme than if they are phonetically unrelated, whereas poor readers are not penalized in recall by rhyming items. This result has been reported for a variety of items, ranging from letter strings to sentences (Mann, Liberman, \& Shankweiler, 1980; Shankweiler, Liberman, Mark, Fowler, \& Fischer, 1979). Poor readers, then, have failed to show phonetic confusability effects on recognition memory tests and recall of phonetically similar material. The interpretation of this finding has been that poor readers have difficulty in establishing phonetic codes.

Unfortunately for this claim, equal numbers of inconsistent data are now available. McFarland and Rhodes

We sincerely appreciate the cooperation of John S. Reynolds, Anne Yelton, and the teachers, students, and parents of the Reidsville, NC, schools. Please address correspondence to either author at: Department of Psychology, University of North Carolina, Greensboro, NC 27412.
(1978) reported comparable recall for good and poor readers following a phonetic orienting task. Morrison, Giordani, and Nagy (1977) found that poor readers recognized abstract figures, which could not be labeled (Morrison, 1978), no better than they did geometric figures or letters, both of which can be phonetically coded. Moreover, several studies have reported typical disruption of poor readers' recall under conditions of phonetic similarity, and in all cases, the pattern of performance was quite similar to that of good readers (Johnston, 1982; Mohan, 1975; Wilson, 1977; Hall, Wilson, Humphreys, Tinzmann, \& Bowyer, 1983; Wolford \& Fowler, 1983). Thus, the overall support for phonetic coding deficiency from studies of memory for phonetically similar items is quite mixed.

The purpose of the present experiment was explicitly empirical, to compare the performance of normal and disabled readers on a task different from previously used tasks. In this experiment, children were given a standard release-from-proactive-inhibition (PI) task in which three dimensions of similarity were present-semantic, visual, and phonetic. The release-from-PI paradigm is among the paradigms routinely used to infer dimensions of encoding and, although no one experiment or task would be totally convincing, the converging evidence from the PI paradigm should be informative.

The strongest prediction from the phonetic coding deficiency hypothesis would entail a specific interaction between reading ability and type of similarity. If poor readers are markedly deficient in phonetic coding, phonetically similar words should not produce confusion in poor readers to the extent that they do in normal readers. Furthermore, the pattern of performance should be similar between normal readers and poor readers on other dimensions of similarity. That is, poor readers should demonstrate typical PI effects with semantically and visually similar words.

\section{METHOD}

\section{Subjects}

The subjects were 20 normal and 20 reading-disabled children, all of whom were completing their 3 rd year of public school. Intellectual 
and reading abilities were indexed, respectively, by the Slosson Intelligence Test (Slosson, 1963) and the reading subtest of the Wide Range Achievement Test (Jastak, Bijou, \& Jastak, 1965). Good and poor readers were comparable in age ( 9 years, 2 months vs. 9 years, 9 months), and the average IQ scores of both groups were in the normal range (107.2 for good readers vs. 103.4 for poor readers). The mean reading level for good readers was 5.2, and that for poor readers was 2.6.

\section{Design}

At each of the two levels of reading ability, three main variables were manipulated within subjects. Three types of similarity (visual, phonetic, and semantic) were seen by each child. A particular level of similarity was maintained across three trials. On the fourth trial of the series, the child either continued with the particular level of similarity (nonshift condition) or received a set of items different in similarity from those on Trials 1-3 (shift condition). Thus, the similarity of Trial 4 items to those of Trials 1-3 constituted the third important within-subjects variable (shift-nonshift). Each child was exposed to all levels of similarity, and within each level of similarity, each child participated in one shift series and one nonshift series. The stimuli were counterbalanced across subjects, however, such that performance in the shift and nonshift conditions was based on recall of exactly the same words. In addition, the order of shift and nonshift sequences was counterbalanced across subjects for each type of similarity.

\section{Stimuli}

All words were selected from norms of the most frequently used words in the spontaneous writing of second- and third-graders (Rinsland, 1945). On the basis of these norms, average word frequency was approximately equal across similarity type.

For the phonetic and semantic series, the triads were constructed such that the first letters of the three words were not the same and such that the three words were as visually dissimilar as possible. For the visual similarity series, the triads were constructed such that the first letters in the words of a particular similarity class were the same and the last letters of the words within a triad were dissimilar, and such that none of the words in a particular similarity class rhymed with each other. Whenever possible, the vowel sounds of the three words constituting a triad were kept as dissimilar as possible. All the items in the visual similarity series were four-letter monosyllabic words. These restrictions were adopted on the basis of findings attributing judgments of visual similarity to word length and letter configuration and to the similarity of the initial letters (e.g., Posnansky \& Rayner, 1977).

The latter criterion, however, poses a problem for purposes of this study. By maintaining the same first letter across the visually similar words, visual similarity may be confounded with phonetic similarity. Any effects of visual similarity might then be due to the first letters of the words rather than to the visual patterns of the words. To assess this potential confounding, an independent control group of normal readers received a modified version of the visual similarity manipulation. In this control condition, the shift trial consisted of words whose visual patterns were quite different from those of the words on Trials 1-3 but whose first letters remained constant over all four trials. Thus, if our manipulation of visual similarity were effective only because visually similar words had the same first letters, no release from PI should be obtained in the control condition.

\section{Procedure}

There were four pretraining trials and four trials in each of the similarity series. Pretraining and testing were conducted according to the same procedure. The children were tested individually in their school setting. The experimenter sat next to the child and slowly explained the procedure. At the beginning of each trial, the experimenter said "ready," and then a card with a triad was exposed. The card was in view for a maximum of $15 \mathrm{sec}$, during which time the child was asked to read the words aloud. The card was removed immediately after the child had read the last word. In the event that a child was unable to read a word within $5 \mathrm{sec}$, or read a word incorrectly, the experimenter read the word aloud and asked the child to repeat it. The child was then asked to attempt the next word. During a 10-sec delay interval, a series of twodigit numbers was read aloud by the experimenter, and the child was required to repeat each number aloud as it was being presented. At the end of the retention interval, the experimenter said "go," as a signal to the child to attempt recall. The child was allowed $10 \mathrm{sec}$ for oral recall of the words.

\section{RESULTS}

The results contain information concerning both reading performance and memory performance, which are presented separately. Furthermore, memory performance was examined in terms of both absolute recall and recall conditionalized on correct reading.

\section{Reading Performance}

Good readers read substantially more words than poor readers $[\mathrm{F}(1,38)=29.04, \mathrm{MSe}=4.69]$. Type of similarity also reliably affected reading $[\mathrm{F}(2,76)=25.14$, MSe $=.50$ ]. Both good and poor readers' performances appear to decline systematically from semantic to phonetic to visual similarity; however, absolute comparisons of type of similarity are very tenuous because of the difficulty of equating similarity across the three dimensions. More informative is the interaction between reading ability and type of similarity $[\mathrm{F}(2,76)=8.01, \mathrm{MSe}=.50]$. As revealed by subsequent Newman-Keuls analysis, this interaction was attributable to the disproportionate disruption of the poor readers' performance on visually similar words. It is interesting to note that trials exerted no reliable effect upon reading performance $[\mathrm{F}(3,228)=1.42$, $\mathrm{MSe}=.28]$ and that the effect of trials did not reliably interact with type of similarity $[F(6,228)=2.09$, MSe $=.28]$. Thus, the differential effect of similarity type on the reading performance of good and poor readers was present on Trial 1 and did not systematically increase with further exposure to the particular similarity dimensions.

\section{Absolute Recall Performance}

The logic of the release-from-PI paradigm dictates two important dependent measures: Performance over Trials 1-3 indicates the buildup of PI, and performance on Trial 4 indicates release from PI. Hence, the recall data for Trials 1-3 and for Trial 4 were analyzed separately. Furthermore, separate analyses were performed for each type of similarity because of the hazards of generalizing across dimensions of similarity.

Under conditions of semantic similarity, recall performance declined over Trials 1-3 $[\mathrm{F}(2,76)=9.97$, MSe $=.73]$. The decline in recall was comparable for good and poor readers, as indicated by the lack of a reliable reading ability $\times$ trials interaction $[F(1,76)=2.91$, MSe $=1.08]$. Performance on Trials 1-3 was comparable in the shift and nonshift conditions $[\mathrm{F}(1,38)=<1]$, and this variable did not interact reliably with trials. No reliable effect was exerted on memory over Trials $1-3$ by reading ability $[\mathrm{F}(1,38)=2.72$, MSe $=.88]$. On Trial 4 of semantic similarity, the only reliable effect was due to the shift-nonshift variable $[\mathrm{F}(1,38)=4.92, \mathrm{MSe}=1.01]$. Thus, absolute recall of semantically similar items did not differ reliably for good and poor readers, both of whom demonstrated buildup and release of PI. 
With phonetically similar words, recall declined across Trials $1-3[\mathrm{~F}(2,76)=19.88, \mathrm{MSe}=.88]$, and this decline was comparable for good and poor readers, as indicated by a lack of reliable interaction between reading ability and trials $[F(2,76)<1]$. There was no reliable effect of shift-nonshift $[\mathrm{F}(1,38)<1]$, and this variable did not interact with trials $[\mathrm{F}(1,38)<1]$. Good readers did recall more words than poor readers over Trials $1-3[F(1,38)$ $=6.10, \mathrm{MSe}=1.50 \mathrm{]}$. On Trial 4 of phonetic similarity, the only effect was due to higher recall in the shift than in the nonshift condition $[\mathrm{F}(1,38)=6.90, \mathrm{MSe}=1.04]$. Thus, good readers recalled more phonetically similar words than poor readers over Trials 1-3, but both groups were subject to the buildup and release of PI.

Recall performance also declined over Trials 1-3 under conditions of visual similarity $[\mathrm{F}(2,76)=5.30, \mathrm{MSe}=$ .92]. This decline in performance did not interact reliably with reading ability $[\mathrm{F}(2,76)<1]$, and the trial $\times$ shift-nonshift interaction was not significant $[F(2,76)<1]$. Memory performance was slightly higher in good readers on Trials $1-3$ of visual similarity $[\mathrm{F}(1,38)=3.84$, MSe $=1.10]$. On Trial 4 , the shift condition led to marginally higher performance than the nonshift condition $[\mathrm{F}(1,38)$ $=3.07, \mathrm{MSe}=1.04]$, and the interaction of reading ability $\times$ shift-nonshift was also marginally reliable $[\mathrm{F}(1,38)$ $=3.07, \mathrm{MSe}=1.04 \mathrm{]}$. Thus, under conditions of visual similarity, good readers recalled more words than poor readers, and both groups were subject to the buildup of PI. The marginally reliable reading ability $\times$ shift-nonshift interaction on Trial 4 suggests, however, that release from visual similarity PI was greater in good readers.

In summary of the absolute recall data, good and poor readers' performances were remarkably comparable as a function of type of similarity. Both good and poor readers were subject to buildup of PI along all similarity dimensions, which is usually interpreted as evidence for encoding that dimension. Release from PI was comparable under conditions of semantic and phonetic similarity, a further indication of encoding on those dimensions. Good readers showed slightly more release on the visual dimension, but this difference was of marginal significance. Although the similarity in absolute recall of good and poor readers is striking, these data are based on words that were correctly read and on words that had to be read to the child. Since the controversy concerning differential coding abilities in good and poor readers concerns situations in which visual stimuli are recoded, recall performance conditionalized upon correct reading bears most directly upon questions of differential coding.

\section{Recall Given Correct Reading}

The average percentage of words read and recalled is shown in Table 1. Subsequent analysis of the data in Table 1 suggests that the pattern of conditional recall differs from that of absolute recall only with visual similarity.

The probability of recall given correct reading under conditions of semantic similarity declined over Trials 1$3[\mathrm{~F}(2,76)=15.62, \mathrm{MSe}=1.42]$, and this decline was comparable for good and poor readers as well as in the
Table 1

Probability of Correct Recall Given Correct Reading

\begin{tabular}{lcccccc}
\hline \multirow{2}{*}{ Test Series } & & \multicolumn{2}{c}{ Good Readers } & & \multicolumn{2}{c}{ Poor Readers } \\
\cline { 3 - 4 } \cline { 5 - 6 } Semantic & Trial & Shift & Nonshift & & Shift & Nonshift \\
& 1 & 94 & 75 & 60 & 72 \\
& 2 & 70 & 66 & & 45 & 60 \\
& 3 & 63 & 53 & 53 & 60 \\
Rhyme & 4 & 80 & 59 & 66 & 50 \\
& 1 & 71 & 78 & 53 & 55 \\
& 2 & 63 & 55 & 27 & 40 \\
& 3 & 41 & 33 & 23 & 34 \\
Visual Similarity & 4 & 59 & 42 & 46 & 29 \\
& 1 & 53 & 61 & 35 & 31 \\
& 2 & 35 & 42 & 27 & 24 \\
& 3 & 34 & 42 & 29 & 22 \\
& 4 & 46 & 20 & 25 & 25 \\
\hline
\end{tabular}

shift-nonshift conditions. Neither of these variables interacted with trials. Performance was not affected by reading ability $[F(1,38)<1]$ over Trials $1-3$. On Trial 4 of semantic similarity, the only reliable effect upon conditional recall was due to higher recall in the shift than in the nonshift condition $[\mathrm{F}(1,38)=27.49, \mathrm{MSe}=3.44]$.

Conditional recall of phonetically similar stimuli showed exactly the same pattern. Performance declined over Trials $1-3[\mathrm{~F}(2,76)=17.70, \mathrm{MSe}=1.77]$, and this effect did not interact with reading ability or shift-nonshift. Conditional recall of phonetically similar stimuli was not affected by reading ability on Trials $1-3[F(1,38)=3.03$, $\mathrm{MSe}=1.73$ ]. On Trial 4, conditional recall of phonetically similar stimuli was reliably higher in the shift than in the nonshift condition $[\mathrm{F}(1,38)=31.00$, $\mathrm{MSe}=2.97]$. Trial 4 performance was not reliably affected by reading ability.

Conditional recall of visually similar stimuli also declined over Trials $1-3[\mathrm{~F}(2,76)=31.78, \mathrm{MSe}=2.06]$. This decline in performance was not comparable for good and poor readers, as indicated by the reading ability $\times$ trials interaction $[\mathrm{F}(2,76)=3.39, \mathrm{MSe}=2.06]$. Inspection of Table 1 and subsequent Newman-Keuls analysis suggest that this interaction is due to a decline in performance among good readers but not poor readers. Furthermore, good readers recalled more words than poor readers over Trials 1-3 $[\mathrm{F}(1,38)=5.42, \mathrm{MSe}=2.15]$. The poor readers also show no release on Trial 4. Although the shift-nonshift effect was reliable on Trial $4[\mathrm{~F}(1,38)=$ 6.89 , MSe $=1.05]$, the effect of shifting the similarity on Trial 4 was not comparable for good and poor readers, as indicated by a reading ability $\times$ shift-nonshift interaction $[\mathrm{F}(1,38)=7.25, \mathrm{MSe}=1.02]$. Newman-Keuls analysis indicates an improvement on Trial 4 by good readers but not poor readers. Finally, on Trial 4, good readers recalled more words than poor readers $[\mathrm{F}(1,38)=6.90$, $\mathrm{MSe}=1.02]$.

In summary of the conditional recall data, both good and poor readers were subject to the buildup and release of PI along semantic and phonetic dimensions of similarity. However, with visually similar words, poor readers gave no evidence of PI or its release. Thus, for correctly read words, memory performance of poor readers differed 
from that of good readers only when the stimuli were visually similar.

\section{Control Data}

The control condition was designed to analyze the effect of maintaining the same first letter under conditions of visual similarity. Trials 1-3 were identical to those of the visual similarity group. Performance declined over Trials $1-3[\mathrm{~F}(1,14)=5.61, \mathrm{MSe}=1.94]$. Unlike the visual similarity condition, the words on the shift trial in the control condition continued to share the same first letters with words on preceding trials, and performance on Trial 4 was higher in the shift condition than in the nonshift condition of the control group $[\mathrm{F}(1,14)=4.51$, MSe $=$ 2.35]. That is, words whose visual patterns were changed from those of the preceding three trials were better remembered than words whose visual patterns were similar to those of the preceding trials, even though all words shared first letters. Thus, the effects of visual similarity do not appear to be due to encoding of the first letter.

\section{DISCUSSION}

The results of this experiment do not support a strong form of the phonetic coding deficiency hypothesis. Reading-disabled children were influenced by phonetic similarity much as were normal readers, a finding consistent with other recent studies (e.g., Hall, Wilson, Humphreys, Tinzmann, \& Bowyer, 1983; Johnston, 1982; Wolford \& Fowler 1983). Semantic similarity also produced comparable patterns of performance between normal and poor readers, suggesting, contrary to McFarland and Rhodes (1978), that poor readers are not uniformly deficient in semantic coding. Under the conditions of this study, however, visual similarity was devastating to poor readers. Not only did poor readers differ from normal readers on the recall measure, but, more importantly, visual similarity destroyed reading performance.

A reasonable interpretation of these data, as well as of the rampant inconsistency in this literature, may be derived from Vellutino's (1979) hypothesis on reading disability. His idea, actually a form of phonetic coding deficiency, is that disabled readers have difficulty in translating visual information into a phonetic form. If we assume that the difficulty lies generally in this process, and not just in establishing a phonetic code, the hypothesis takes on considerable generality. For example, visual similarity may have disrupted phonetic coding in our experiment by interfering with retrieval of phonetic information. That is, the children may have attempted to retrieve similar phonetic codes for the similar visual patterns. Since the phonetic patterns were quite different for the visually similar words, such attempts would preclude successful reading. Note, however, that the disruption begins with visual similarity, and in this sense, Vellutino's hypothesis is quite useful if considered as the general process of translating visual information to phonetic information.

Even in this general form, however, it is not perfectly clear that reading disability is caused by a processing deficit. As Morrison and Manis (1982) noted, no single processing deficit has been empirically isolated and then logically tied to specific reading disability. The inconsistent findings concerning phonetic coding are testimony to this conclusion. Morrison and Manis suggested that reading disability is caused by the failure to learn the complex rules underlying orthographic-to-phonetic mapping. Although apparently similar to Vellutino's (1979) hypothesis, Morrison and Manis's idea is fundamentally different in that reading disability causes the phonetic or semantic or visual coding deficiencies in laboratory tasks, not vice versa. That is, failure to learn the rules necessary for reading will result in a wide range of differences between normal and poor readers on standard laboratory tasks, but no specific processing deficit can be inferred from these differences. Rather, ensuing research should concentrate on identifying the symbol-sound rules necessary for reading and then establish diagnostic experimental paradigms in which the rule-learning deficit would be apparent.

\section{REFERENCES}

BADDEley, A. D., \& Hitch, C. (1974). Working memory. In G. A. Bower (Ed.), The psychology of learning and motivation (Vol. 8). New York: Academic Press.

BYRNe, B., \& SHEA, P. (1979). Semantic and phonetic memory codes in beginning readers. Memory \& Cognition, 7, 333-338.

ConRad, R. (1972). Speech and reading. In J. F. Kavanagh \& I. G. Mattingly (Eds.), Language by ear and by eye: The relationships between speech and reading. Cambridge, MA: MIT Press.

Crowder, R. G. (1972). Visual and auditory memory. In J. F. Kavanagh \& I. G. Mattingly (Eds.), Language by ear and by eye: The relationship between speech and reading. Cambridge, MA: MIT Press.

Hall, J. W., Wilson, K. P., Humphreys, M. S., TinzmanN, M. B. \& BowYER, P. M. (1983). Phonemic-similarity effects in good vs. poor readers. Memory \& Cognition, 11, 520-527.

JASTAK, I., Bijou, S. W., \& JASTAK, S. R. (1965). Wide Range Achievement Test. Wilmington, DE: Guidance Associates.

Johnston, R. S. (1982). Phonological coding in dyslexic readers. British Journal of Psychology, 73, 455-460.

Liberman, I. Y., \& ShanKWEILER, D. (1980). Speech, the alphabet and teaching to read. In L. B. Resnick \& P. A. Weaver (Eds.), Theory and practice of early reading. Hillsdale, NJ: Erlbaum.

Liberman, I. Y., Shankweiler, D., Liberman, A. H., Fowler, C., \& FisChER, F. W. (1977). Phonetic segmentation and recoding in the beginning reader. In A. S. Reber \& D. Scarborough (Eds.), Toward a psychology of reading: Proceedings of the CUNY conferences. Hillsdale, NJ: Erlbaum.

ManN, V. A., Liberman, I. Y. \& Shankweiler, D. (1980). Children's memory for sentences and word strings in relation to reading ability. Memory \& Cognition, 8, 329-335.

Mark, L. S., Shankweiler, D., Liberman, I. Y., \& Fowler, C. A. (1977). Phonetic recoding and reading difficulty in beginning readers. Memory \& Cognition, 5, 623-629.

MCFARLAND, C. E., \& RHODES, D. D. (1978). Memory for meaning in skilled and unskilled readers. Journal of Experimental Child Psychology, 25, 199-207.

Mohan, P. J. (1975). Acoustic encoding in normal and retarded readers. Child Development, 46, 593-597.

MoRrison, F. J. (1978). Reading disability: Methodological problems in information processing analysis. Science, $200,802$.

Morrison, F. J., GrordanI, B., \& NAGY, J. (1977). Reading disability: An information-processing analysis, Science, 199, 77-79.

Morrison, F. J., \& MANIS, F. R. (1982). Cognitive processes and reading disability: A critique and proposal. In C. J. Brainerd \& M. Pressley (Eds.), Advances in cognitive development: Vol. 2. Verbal processes in development. New York: Springer.

Perfetti, C. A., \& LesGold, A. M. (1978). Discourse comprehension and sources of individual differences. In M. J. Just \& P. A. Carpenter (Eds.), Cognitive processes in comprehension. Hillsdale, NJ: Erlbaum.

POSNANSKY, C. J., \& RAYNER, K. (1977). Visual-feature and response components in a picture-word interference task with beginning and skilled readers. Journal of Experimental Child Psychology, 24, 440-460.

RINSLAND, H. D. (1945). A basic vocabulary of elementary school children. New York: McMillan.

Rozin, P., \& Gleitman, L. R. (1977). The structure and acquisition of reading II: The reading process and the acquisition of the alphabetic principle. In A. S. Reber \& D. L. Scarborough (Eds.), Toward a psychology of reading: The proceedings of the CUNY conferences. Hillsdale, $\mathrm{NJ}$ : Erlbaum.

Shankweiler, D., Liberman, I. Y., Mark, L. S. Fowler, C. A., \& FISCHER, F. W. (1979). The speech code and learning to read. Journal of Experimental Psychology: Human Learning and Memory, 5, 531-545.

SLosson, R. L. (1963). Slosson Intelligence Test for Children and Adults. New York: Slosson Educational Publications.

Vellutino, F. R. (1979). Dyslexia: Theory and research. Cambridge, MA: MIT Press.

WILson, B. J. (1977). Free recall and subjective organization in performance of learning disabled children. Psychological Reports, 40, 117-118.

WOLFORD, G., \& FowLER, C. (1983). Perception and use of information by good and poor readers. In T. J. Tighe \& B. E. Shepp (Eds.), Perception, cognition, and development: An interactional analysis. Hillsdale: NJ: Erlbaum.

(Manuscript received for publication February 19, 1985.) 